\title{
Characteristics of The Sentence in The Qur'anic Story
}

\author{
Adnan Khalid Fadhl ${ }^{*, 1}$, Najeb Wahab Hassan ${ }^{2}$ \\ ${ }^{1}$ Faculty of Arts, Tikrit University, Iraq \\ ${ }^{2}$ Faculty of Education, Garmian University, Iraq \\ * adnanaldosery74@gmail.com
}

\section{KEYWORDS: $\quad$ Sentence, Story, Connotation, Structure, Context.}

\begin{abstract}
:
The holy Qur'an has adopted many methods in conveying its message to people, and among these methods is the style of the story that it has paid special attention to, form and content. The Quranic story has occupied a wide area in the Quranic context, and has actively contributed to its statement, rhetoric, miraculousness and verdicts, in addition to the entertainment it contains for the Messenger (may God bless him and grant him peace). From this standpoint, we will focus our research on the characteristics of the sentence in the context of the Qur'anic story, especially the stylistic characteristics. And what it achieves in terms of statement, significance and influence on the recipient's soul, in addition to achieving the mystery of the Quranic miracles, which is one of its goals for which it was revealed. We have examined these distinct characteristics of the sentence in the Qur'anic story through three axes or demands, namely: First: Verbal and semantic consistency. The second: the combination of compound and simple sentences. Third: the stylistic diversity between the nominative and the actual. This brief research discusses the most important advantages of the sentence in the context of the Quranic story. As a major unit in textual analysis, especially the sentences mentioned in the context of the Makkah story; Because of their importance and distinctive characteristics in the overall analysis of those stories, while not forgetting the civil story and indicating the semantic differences between them. The research reached many results, including that the Qur'an story in the Makkah surahs relied remarkably on the narration of events on short sentences. While the story in the Madinah surahs leaned towards long sentences, including that the Qur'an story relied on simple sentences, especially in dialogue stories, rather than on compound sentences, and also that the expression in actual sentences was overwhelming in the narrative use over nominal sentences what fits the actual sentence in its connotation of renewal, occurrence and movement, unlike the nominal one that denotes permanence and continuity.
\end{abstract}




\title{
خصائص الجملة في القصة القر آنية
}

\author{
أ.م.د. عدنان خالد فضل**1، م.د. نجيب وهاب حسن 2 \\ 1 كلية الآداب، جامعة تكريت، العراق \\ 2 كلية التربية، جامعة كرميان، العر اق اقدابل \\ * adnanaldosery74@gmail.com
}

\section{الكلمات المفتاحية | الجملة، القصة، الدلالة، التركيب، السياق.}

Crossref doi https://doi.org/10.51345/.v32i2.409.g217

\section{ملخص البحث:}

فالقر آن الكريم اعتمد أساليب عديدة في ايصال رسالته الى الناس، ومن ضمن هذه الأساليب هو أسلوب القصة التي أولاها

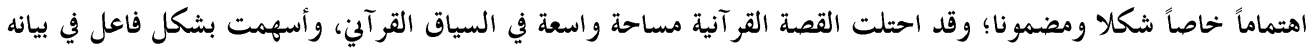

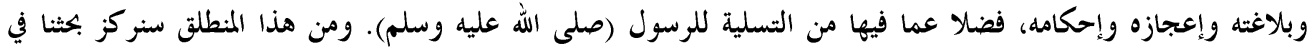

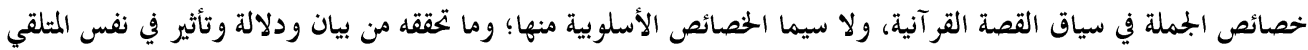

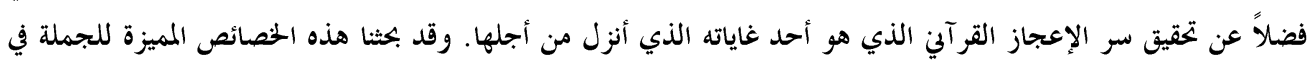

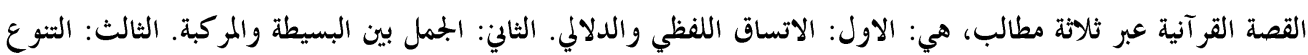

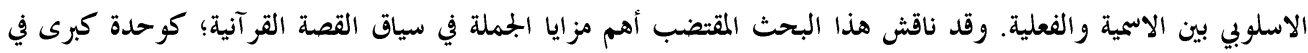

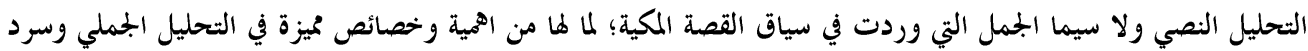

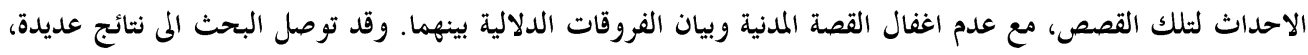

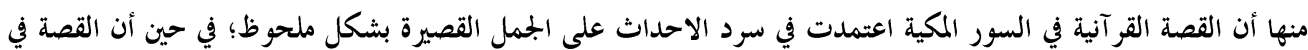

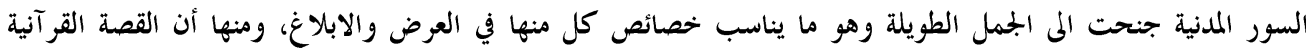

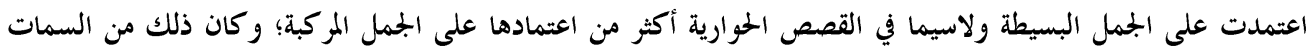

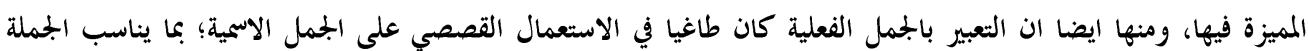

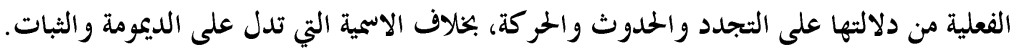

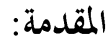

اعتمد القرآن الكريم أساليب عديدة في ايصال رسالته المى الناس، ومن ضمن هذه الأساليب هو أسلوب

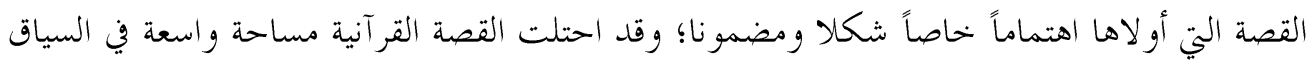

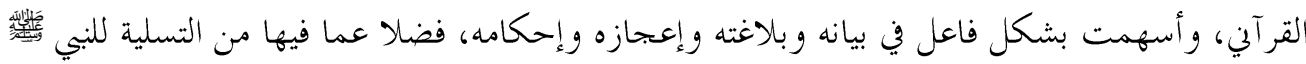


ولا نريد أن نطيل الحديث في تعريفات القصة، وانو اعها او بواعثها في السياق القرآني إذ يمكن الرجوع في ذلك الى مضاها(1)، وانما سنركز بكثنا في خصائص الجملة في سياق القصة القرآنية، ولا سيما

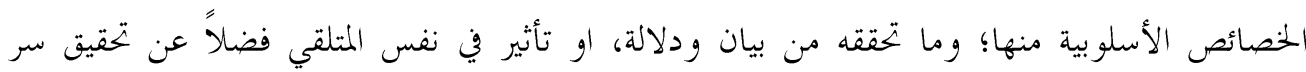

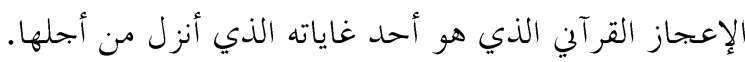
ويمكن معالجة خصائص الجملة في سياق القصة القرآنية عبر ثلاثة محاور او مطالب هي: الاول: الاتساق اللفظي والدلالي. والثاني: الجمل بين البسيطة والمركبة. والثالث: التنوع الاسلوبي بين الجملة الاسمية و الفعلية. و القصة القرآنية في بياذا وبلاغتها تصب في قوالب الاعجاز، ويقوم بناؤها على التراكيب المنفردة التي

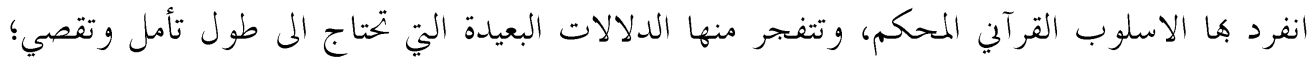

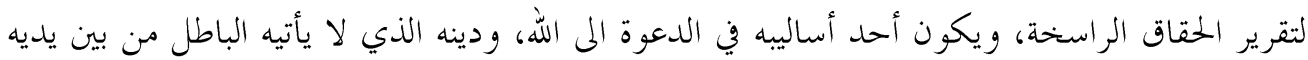

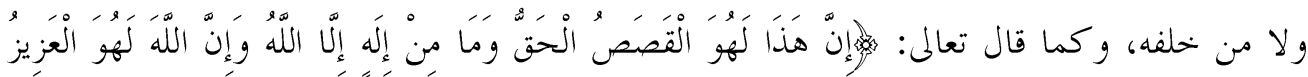

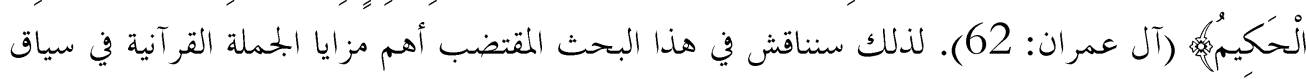
القصة القرآنية كوحدة دلالية كبرى في التحليل النصي؛ ولا سيما الجمل التي وردت في سياق القصة

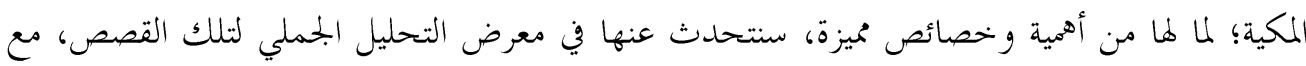
عدم اغفال القصة المدنية، وبيان الفروقات الدلالية بينهما.

\section{المطلب الأول: الاتساق اللفظي والدلالي.}

ولا نقصد هنا بالاتساق اللفظي الاتساق الذي هو من معايير النصية في الدرس اللساني الحديث، وانما نقصد به ان الجملة القرآنية تقع في أنساق متآلفة تنطوي على مشاكلة للدلالة والغايات؛ فيستريح هلذا منا التآلف اللفظي السمع والصوت و النطق؛ ويتكون من اجتماع هذه الجمل على النحو الذي سيقت فيه

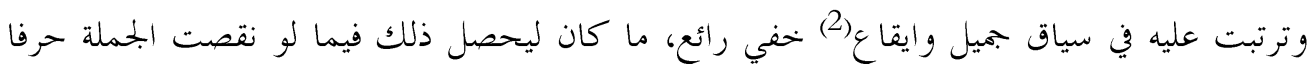

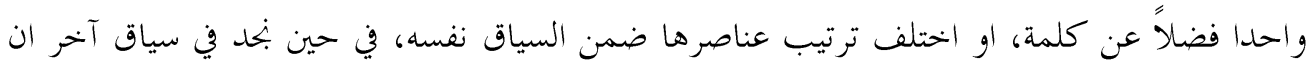
الترتيب يمكن ان يختلف؛ ليؤدي الدلالة في سياقها الذي وضعت له. لقد كانت الجملة في القصة القرآنية -بأنماطها المختلفة- دقيقة في بيان الدلالة القرآنية، فكان كل منها في المكان المناسب له؛ إذ لا يمكن استبدال نمط مكان نمط آخر أو بحيئها على غير الترتيب الذي رتبه يسته

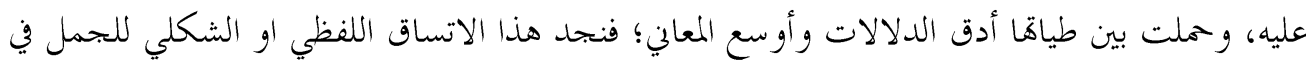


أسلوب القصة القرآنية وتنوعه بين أنواع الجمل الاسمية والفعلية، وكذلك الشرطية، اذا اعتبرناها نوعاً

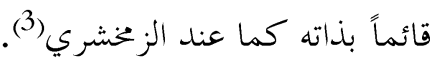

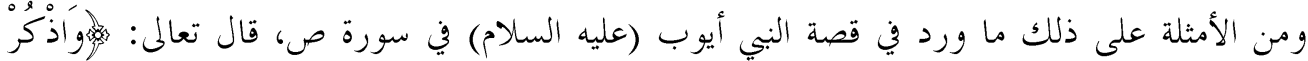

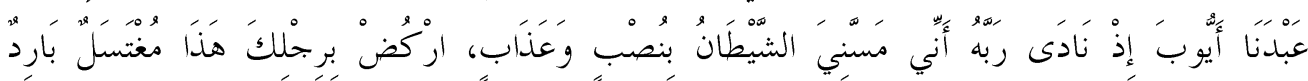

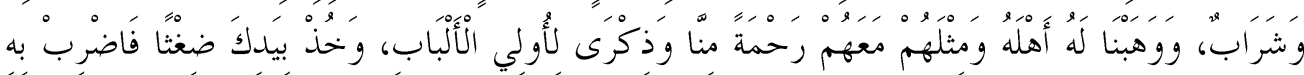

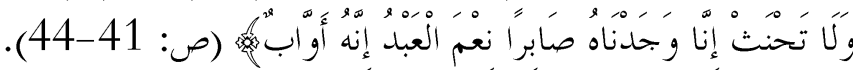

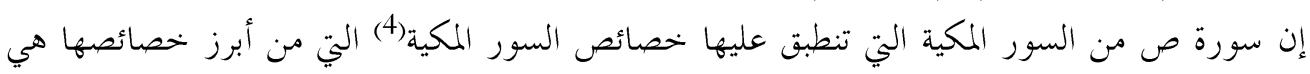
وجود القصص القرآنية، لذلك بنحد في سورة ص أربع قصص وهي:

$$
\begin{aligned}
& \text { 1- داود و الخصمان الآيات }
\end{aligned}
$$

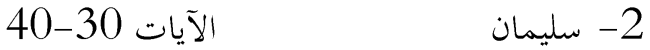

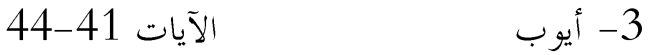

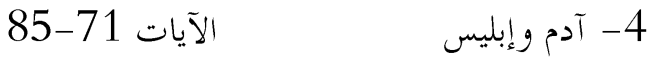

وقد كانت جمل هذه القصص متسقة بين الاسمية والفعلية، وملحقاقما التي كلما زادت هذه الملحقات

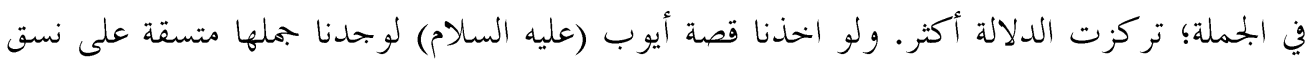
خاص، و كما في الجحدول رقم (1). فالقصة تكونت من أربع عشرة جملة، عشر منها فعلية، وأربع اسمية، وتخلو من الجملة الشرطية، فضلا عن كون معظم جملها ذات النمط العادي القصيرة، خلا جملتين اسميتين مركبتين، ضمتا جملتين فعليتين صغيرتين ولا يوجد تركيب فعلي كبير، وقد طغت الجمل الفعلية ذات الملحقات التي تنوعت بين

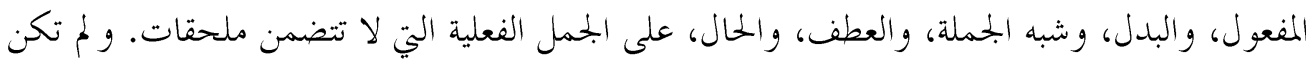

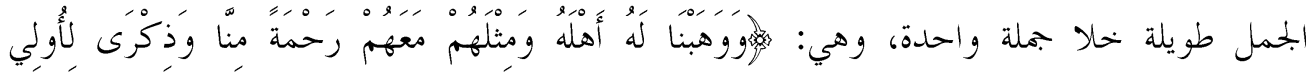

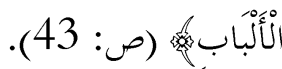
وهذه الجملة هي أطول جملة في سياق القصة، ومع ذلك فهي في غاية الإحكام والاتساق في الالفاظ،

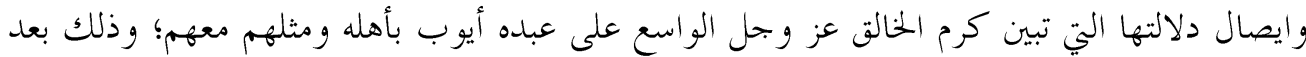
الابتلاء الشديد بالمرض الذي استمر لمدة طويلة، ويعجز البشر عن تحمله، وقد قابل أيوب عليه السلام هذا الابتلاء الصعب بصبر كبير وعظيم؛ فنال رحمة ربه -عز وجل- ورضوانه بصبره وبتحلده حتى نال وصفه بأنه (أواب)(5). 


\begin{tabular}{|c|c|c|c|c|}
\hline ملاحظات & السمية & فعلية & الجملة & \\
\hline \multirow[t]{2}{*}{ تتضمن اضافة } & & - & اذكر عبدنا ايوب & 1 \\
\hline & & - & نادى ربه & 2 \\
\hline مر كبة & - & & اني مسني الشيطان & 3 \\
\hline \multirow[t]{2}{*}{ تتضمن عطفا } & & - & مسين الشيطان بنصب وعذاب & 4 \\
\hline & & - & اركض برجلك & 5 \\
\hline تتضمن عطفا & - & & هذا مغتسل بارد وشراب & 6 \\
\hline طول الملحقات & & - & وهبنا له اهله ومثله معهم & 7 \\
\hline \multirow[t]{3}{*}{ اختلاف الترتيب } & & - & خذ بيدك ضغنا & 8 \\
\hline & & - & اضرب به & 9 \\
\hline & & - & لا تحنث & 10 \\
\hline \multirow[t]{4}{*}{ مر كبة } & - & & انا و جدناه صابرا & 11 \\
\hline & & - & وجدناه صابرا & 12 \\
\hline & & - & نعم العبد & 13 \\
\hline & - & & انه اواب & 14 \\
\hline
\end{tabular}

و اذا انعمنا النظر في جمل هذه القصة؛ وجدناها مفعمة بالحر كة والحيوية (نادى، مسين، اركض، وهبنا، خذ، اضرب، ......) وهذا من خصائص الجملة الفعلية اليت تواكب الحلدث والحركة بخلاف الجملة الاسمية التي تدل على الدوام و الثبوت(6). لذلك عبر عن المغتسل الذي سيجعله الله دواء" لسقمه بالجملة الاسمية (هذا مغتسل بارد وشراب)، و كذلك لثبوت صفة الأواب واستقرارها في جملة (إنه أواب)، على انه عليه السلام هو العبد الصابر الأواب ومع حالة السقم التي مر ها فلم تنفك عنه هذه الصفة ابداً. و نرى جلياً في جمل هذه القصة ذلك التناوب بين العلو والانخفاض والحركة والسكون، بين تراكيب حادة وأخرى رقيقة تبعث النفس على الهدوء و الاستقرار، و كان المتلقي بين كثير من الدلالات القصيرة و المختصرة التي توحي هها الألفاظ المستعملة، والمتآلفة في اتساق دقيق ومعجز؛ بما يناسب الاسلوب المكي للآيات والجمل في عرض المشهد القصصي بجسداً بأسلوب المدح الذي على الرغم من انتمائه الى النمط 
الفعلي؛ يوحي بثبوت الصفة الحسنة للممدوح وملازمتها، وبأسلوب الجملة الاسمية على الرغم من قلتها في السياق فقد كانت بمثابة الختام للقصة القصيرة التي أجملت مناقب النبي أيوب عليه السلام كلها بلفظة

$$
\text { واحلدة وهي (الأواب)(7). }
$$

والملاحظ هنا في جمل هذه القصة هي لو اننا نظرنا الى كل جملة من جمل هذه القصة على حدة؛ لكانت عادية لا تعطي ذلك التأثير، وتلك الدلالة التي تعطيها جمل السياق بحتمعة في ذلك الاتساق اللفظي الذي هن هن نهن بصدده في مثل هذه المواضع والسياقات في قصص القرآن الكريم.

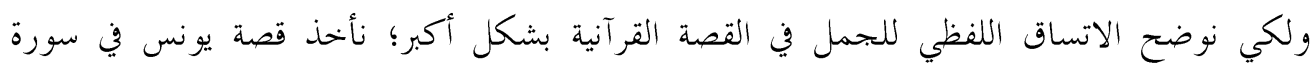

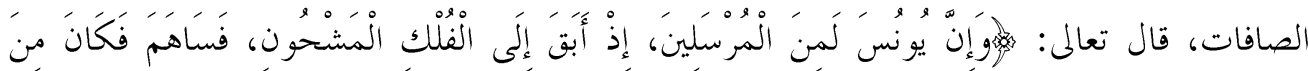

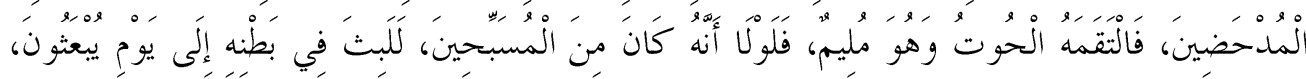

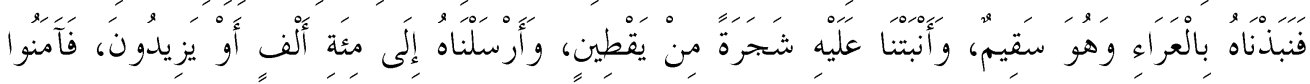

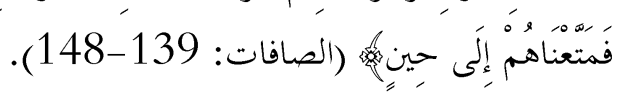
وسورة الصافات من سور المكية، وتتضمن القصص التالية:

$$
\begin{aligned}
& \text { الآيات: } 75 \text { - } 82 \\
& \text { 1- نوح (مختصرة) } \\
& \text { الآيات: 83-113 } \\
& \text { 2- ابراهيم (احداث مختصرة) } \\
& \text { الآيات: } 114 \text { - } 122
\end{aligned}
$$

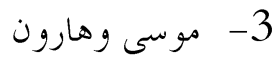

$$
\begin{aligned}
& \text { الآيات: } 123 \text {-132 } \\
& \text { 4- الياس وقومه - موسى ومارون } \\
& \text { الآيات: 1333-138 } \\
& \text {-5 - لوط } \\
& \text { الآيات: } 139 \text { - } 148 \\
& \text { 6- يونس - لوط }
\end{aligned}
$$

ويغلب على هذه القصص طابع الاختصار كسمة عامة للسور المكية، وبالنسبة لقصة يونس (عليه السلام) فقد وردت أربع مرات(8)، وكانت اكثر تفصيلا في سياق سورة الصافات، و كانت الجمل الإل فيها كما مبين في الجدول رقم (2). وهكذا تتكون القصة من خمس عشرة جملة، منها اثنتا عشرة جملة فعلية، وجملتان اسميتان، وجملة شرطية

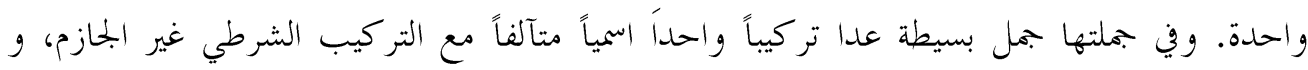
تر كيب فعلي صغير؛ و كان في غاية الدقة والبيان والاتساق اللفظي والدلالي، والترتيب بحسب التبع الأهمية المعنوية، على الرغم من وجود الملحقات الأخرى في التركيب. 


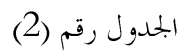

\begin{tabular}{|c|c|c|}
\hline ملاحظات & نوعها & الجملة \\
\hline دخل عليها اللام & فعلية & ان يونس لمن المرسلين \\
\hline \multirow[t]{5}{*}{ تتضمن ملحقات } & فعلية & أبق الى الفلك المشحون \\
\hline & فعلية & فساهم \\
\hline & فعلية & فكان من المدحضين \\
\hline & فعلية & التقمه الحوت \\
\hline & |سمية & وهو مليم \\
\hline غير جازم & شرطية & فلولا انه كان من المسبحين \\
\hline ملحقات & فعلية & فلبث في بطنه اللى يبعثون \\
\hline \multirow[t]{2}{*}{ ملحقات } & فعلية & فنبذناه في العراء \\
\hline & اسمية & وهو سقيم \\
\hline ملحقات & فعلية & انبتنا عليه شجرة من يقطين \\
\hline ملحقات & فعلية & ارسلناه المى مئة الف \\
\hline \multirow[t]{2}{*}{ معطوفة } & فعلية & او يزيدون \\
\hline & فعلية & فآمنوا \\
\hline ملحقات & فعلية & فمتعناهم الى حين \\
\hline
\end{tabular}

و نلاحظ ان الاغلبية كانت للجمل الفعلية، تتخللها الجمل الاسمية، وتتوسطها الجملة الشرطية، وهذا التناسق بين الجمل جاء لبيان الحال الذي كان عليه النبي يونس (عليه السلام) وهو في أشد الظروف

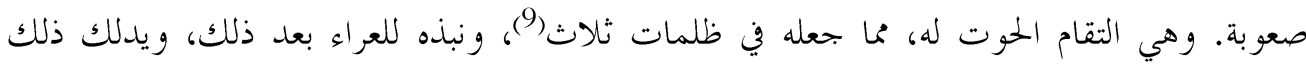
الاتساق اللفظي للجملتين الفعليتين مع الجملتين الاسميتين على تقابل فريد من نوعه: 1- فالتقمه الحوت وهو مليم.

2- فنبذناه بالعراء وهو سقيم.

وهو تقابل كامل ومتكامل بين التركيبين من حيث الاسمية والفعلية، فضلا عن التقابل الدلالي في الشدة

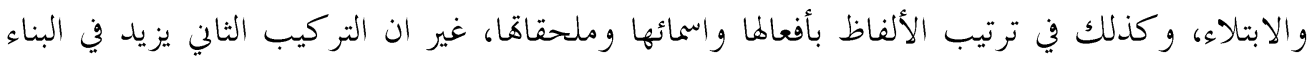
التركيبي بالجار والمجرور (بالعراء)، مع ملاحظة تصدر الجملتين الاسميتين بواو الحال، واسمية الجملة

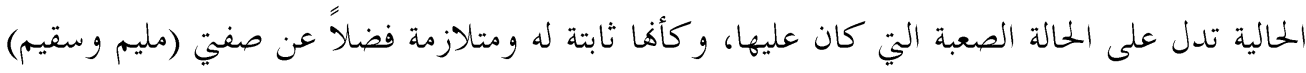


التي تدل بشكل أكثر على ثبات هذه الصفات؛ لأها جاءت على صيغة الصفة المشبهة التي تدل على

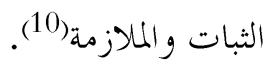

وتتوسط هاتين الجملتين الحاليتين الجملة الشرطية أو التركيب الشرطي الذي ينضوي على جملة اسمية

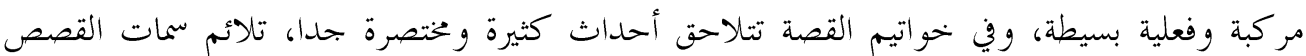
الملكي التي تبعد عن التفصيل، وتذكر الضروري منها، وهو هنا التسبيح الذي أنقذ النبي يونس (عليه السلام) من البقاء في بطن الحوت الى يوم يبعثون، ثم الشجرة التي أنبته الله عليها، ثم إرساله نبيا الى القوم لهدايتهم. و كل ذلك تم في تناسق لفظي دلالي غاية في الدقة والروعة والجمال.

\section{المطلب الثاين: الجممل بين البسيطة والمر كبة(11).}

ونقصد بذلك أن الاستعمال القرآي للجمل في القصة القرآنية، ينوع في استعمال الجملتين البسيطة والمركبة مع إيثار البسيطة على المركبة بشكل ملفت، وهذه الميزة في الاستعمال تتيح للجملة القرآنية

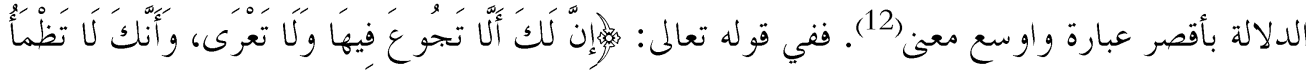

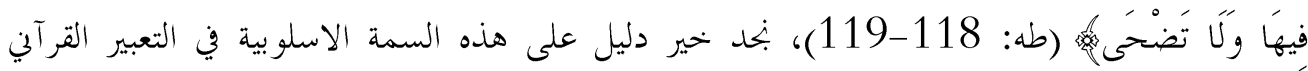
بشكل عام -في القصة وغيرها- فقد أجمل الله عز وجل جميع الضمانات لادم (عليه السلام) بعد خلقه،

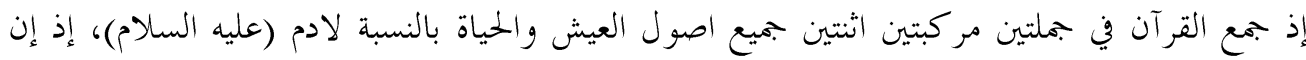

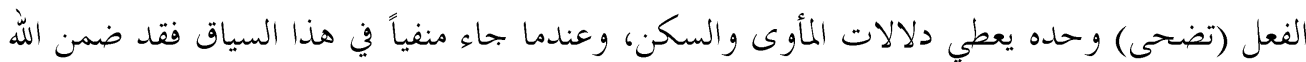

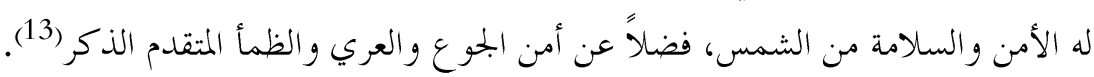

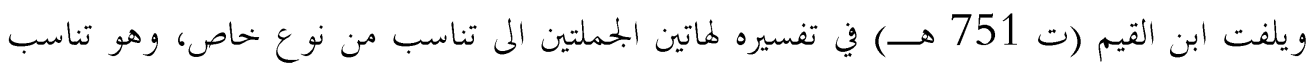

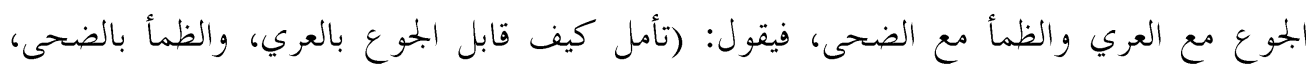

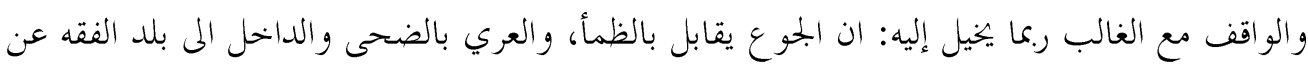

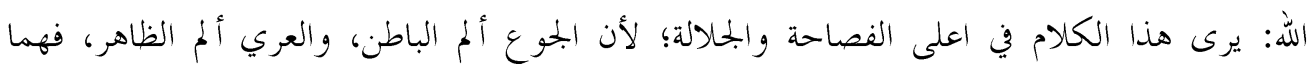

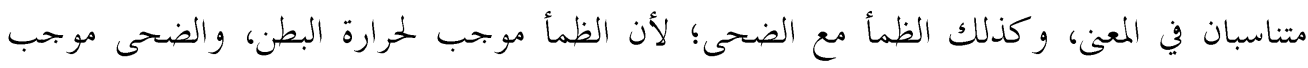
لحرارة الظاهر فاقتضت الآية نفي جميع الآفات ظاهراً و باطناً)(14).

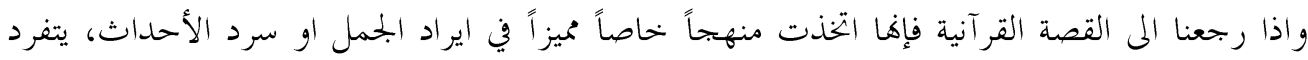
من خلاله الاسلوب القرآي بميزات عديدة، منها الترتيب الزمين وعدم ذكر غير الضروري من الاحداث

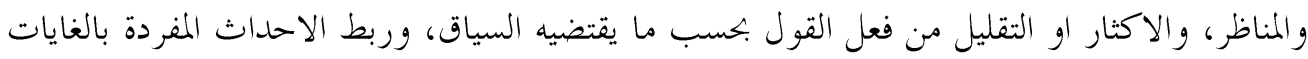

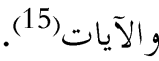


يضاف الى ذلك عوامل الربط الاخرى، و لاسيما اللغوية والاسلوبية، ومنها قدرة الجمل على التضافر، و اقصد هنا الفعلية والاسمية؛ واعطاء جمل مركبة، أو بسيطة، وهذا ما تتطلبه الحبكة الاسلوبية في القصة القر آنية، ولكي ندل على ذلك سنعرض الجمل المستعملة في قصة قارون في سورة القصص، قال تعالى:

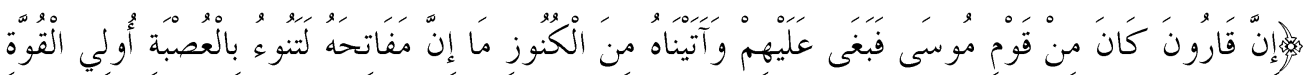

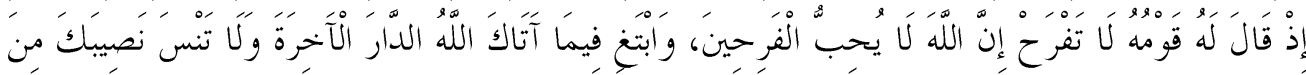

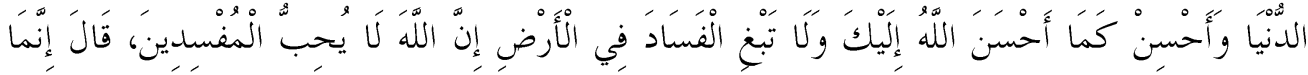

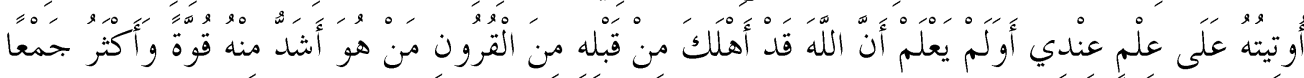

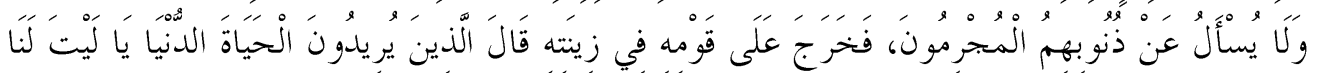

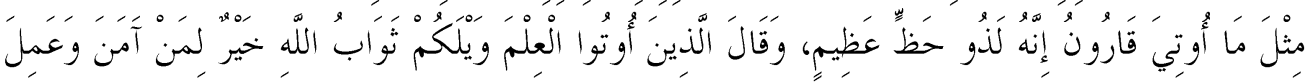

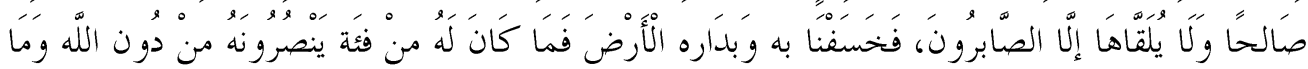

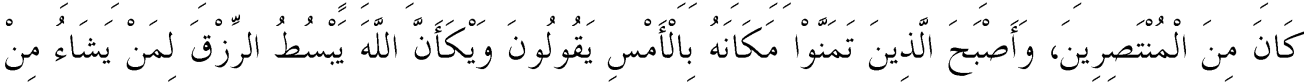

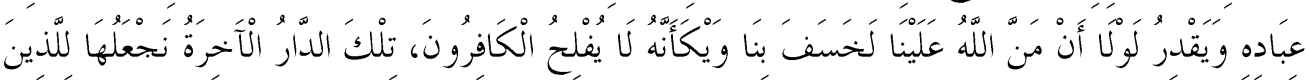

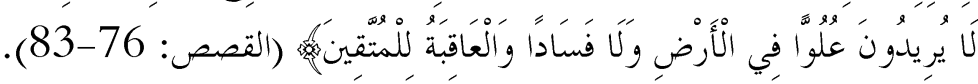
وسورة القصص كما هو معلوم من السور المكية إلا بعض آياها مدنية(16). وتتضمن قصة موسى (عليه السلام) وقصة قارون: قصة موسى كاملة الآيات 3-43، وقصة قارون كاملة الآيات 76- 83. ووردت قصة قارون ايضاً في سورة العنكبوت بشكل مختصر، وهي ايضاً مكية)

واذا تأملنا الجمل في سياق هذا القصة وجدناها كما مبين في الجلدول رقم (3).

الجدول رقم (3) يبين أنو اع الجمل وتراكيبها التي وردت في قصة قارون

\begin{tabular}{|c|c|c|}
\hline بسطة/مر كبة & البمية/فعلية & 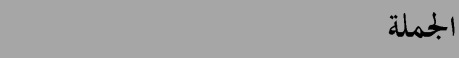 \\
\hline 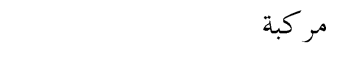 & المية - ماسة & 1. ان قارون كان من قوم موسى \\
\hline بسيطة & فعلية & 2. بغى عليهم \\
\hline بسيطة + ملحقات & فعلية & 3. اتيناه من الكنوز \\
\hline 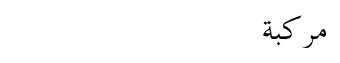 & 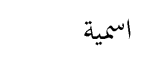 & 4. ان مفاتيحه لتنوء بالعصبة اولى القوة \\
\hline بسيطة تتضمن تقديماً وتاخيراً & فعلية & 5. قال له قومه \\
\hline بسيطة & فعلية & 6. لا تفرح \\
\hline
\end{tabular}




\begin{tabular}{|c|c|c|}
\hline 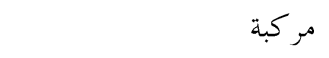 & 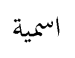 & 7. ان الله لا يحب الفرحين \\
\hline بسيطة & فعلية & 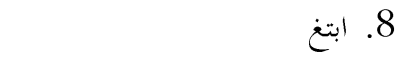 \\
\hline بسيطة + ملحقات & ف معلية & 9. أتاك الله دار الاخرة \\
\hline بسيطة + ملحقات & فعلية & 10. ل لا تنسى نصيبك من الدنيا \\
\hline بسيطة & فعلية & 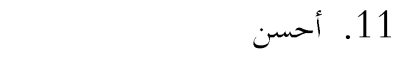 \\
\hline بسيطة + ملحقات & فعلية & 12. لاتبغ الفساد في الارض \\
\hline 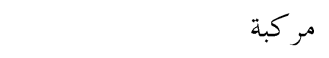 & 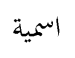 & 13. ان الله لا يحب المعتدين \\
\hline بسيطة + ملحقات & ف معلية & 14. قال أوتيته على علم عندي \\
\hline مركبة - متعدي الم مفعولين & ف معلية & 15. يعلم ان الله قد اهلك \\
\hline 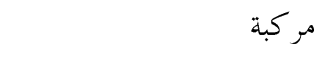 & 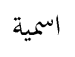 & 16. ان الله قد اهلك \\
\hline بسيطة + ملحقات & فعلية & 17. اهلك من قبله من القرون \\
\hline بسيطة + ملحقات & 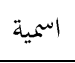 & 18. هو أشد منه قوة \\
\hline بسيطة + تقديماً وتاخيراً & فعلية & 19. لا يسال عن ذنوبهم المجرمون \\
\hline بسيطة + ملحقات & فعلية & 20. خرج على قومه في زينته \\
\hline بسيطة & فعلية & 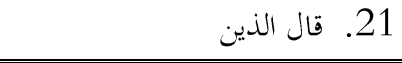 \\
\hline بسيطة + ملحقات & فعلية & 22. يريدون الحياة الدنيا \\
\hline بسيطة + ملحقات & فعلية & 23. ياليت لنا مثل ما \\
\hline بسيطة & فعلية & 24. أوتي قارون \\
\hline بسيطة + ادوات تو كيد & 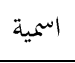 & 25. انه لذو حظ عظيم \\
\hline بسيطة & فعلية & 26. قال الذين \\
\hline بسيطة & ف معلية & 27. أوتوا العلم \\
\hline بسيطة + ملحقات & اسمية & 28. و يلكم ثواب الله خير \\
\hline بسيطة & فعلية & 29. عمل صالحنُ \\
\hline بسيطة + ملحقات & فعلية & 30. لا يلقاها الا الصابرون \\
\hline بسيطة + ملحقات & فعلية & 31. خسفنا به وبداره الارض \\
\hline بسيطة + ملحقات+تقديم & فعلية & 32. ما كان له من فئة \\
\hline بسيطة + ملحقات & فعلية & 33. ينصرونه من دون الله \\
\hline بسيطة فعلها ناقص & فعلية & 34. ماكان من المنتصرين \\
\hline
\end{tabular}




\begin{tabular}{|c|c|c|}
\hline مر كبة + ملحقات & فعلية & 35. اصبح الذين تمنوا مكانه بالامس \\
\hline بسيطة & فعلية & 36. يقولون \\
\hline 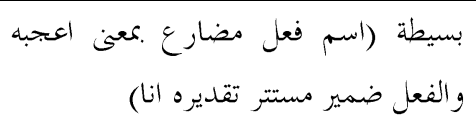 & | - اسمية & 37. يكأن \\
\hline 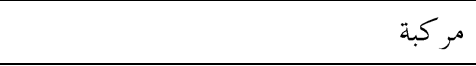 & 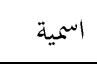 & 38. ـ ويكأن الله يبسط الرزق \\
\hline بسيطة + ملحقات شبة جملة & فعلية & 39. يشاء من عباده \\
\hline شرط غير جازم مركبة & 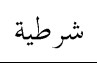 & 40. لو لا أن من الله علينا لخسف بنا \\
\hline بسيطة اسك فعل مضارع & 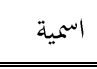 & 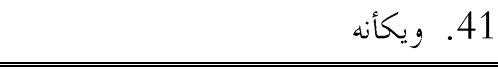 \\
\hline 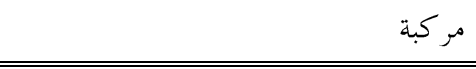 & 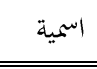 & 42. ويكأنه لا يفلح الكافرون \\
\hline بسيطة & فعلية & 43. لا يفلح الكافرون \\
\hline مركبة + ملحقات & 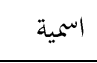 & 44. تلك دار الاخرة بنعلها للذين \\
\hline بسيطة + ملحقات & فعلية & 45. ل لا يريدون علواُ في الارض ولا فسادا \\
\hline 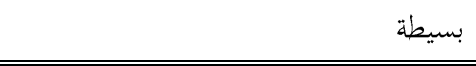 & اسمية & 46. العاقبة للمتقين \\
\hline
\end{tabular}

وهكذا نرى ان القصة تألفت من ست وأربعين جملة، واحدة منها شرطية، بأداة شرط غير جازمة، وأربع عشرة جملة اسمية، خمس منها جمل بسيطة، والتسع الأخرى مر كبة؛ أي إن اخبارها جمل فعلية، وواحدة وتلاثين جملة فعلية. منها جمل فعلية صغرى وهي الاغلب، ومنها جمل بسيطة طويلة من خلال الملحقات. وان اغلب افعالها مبنية للمعلوم وأقلها للمجهول؛ للعلم به وهو الله تعالى. وضمت هذه الجمل تقديما وتأخيرا في رتب عناصرها؛ بحسب الغرض الدلالي الذي حصل من أجله ذلك التقلديم و التأخير. كما ضمت اساليب التوكيد و اغلبها جاءت (إن واللام المزحلقة) وملحقات كثيرة جدا، تنوعت ما بين النعت، و العطف، و الجار والمجرور، و الظرف، و المفعول به، و التمييز، و المضاف اليه. و يتضح من خحلا التحليل الجملي السابق ان الجمل المركبة قد شغلت حيزا لا بأس به من سياق عرض القصة، وأن هذه الجمل بدأت بالاسم او مع أحد النواسخ (أن) وجاء ركنها الصغير جملة فعلية، وهذا التركيب بطبيعته لا يخلو من التعقيد الا انه بلا غاية في الاتساق والمرونة اللفظية والترتيب الجملي الذي أدى كثيراً من الدلالات بأقصر الطرق مع أدق التفاصيل، واختصر الاحداث الكثيرة المتسلسلة زمنياً. ونلاحظ ايضاً ان الغلبة كانت للجمل البسيطة (التركيب الجملي البسيط)، وهذه سمة مميزة من السمات الأسلوبية للجملة في القصة القرآنية بشكل عام، وفي هذه القصة بشكل خاص. او الاسلوب القصي 
المكي او في السور المكية؛ وذلك لأن القصة مبناها على عنصر الحوار؛ وهو عامل رئيس ومهم في الاسلوب التأثيري الذي تتمتع به القصة؛ ليكسبها حيوية وإثارة للانتباه، ووسيلة في ايصال المعنى ونئ والحدث بأقل الطرق وأسلمها صياغة وبلاغة وبيان.

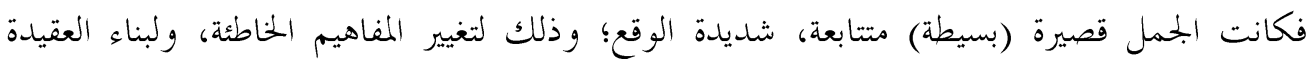
الصحيحة. كما هو الحال في معالجات القصص المكي بشكل عام. في حين لو تأملنا القصص المدني لوجدنا فيه الغلبة للجمل الطويلة المتفرعة الزاخرة بالاعتراضات وشرح الجزئيات في حال الهدوء وبناء الانسان و المجتمع وهذه سمة في القصص المدني عامة(18).

\section{المطلب الثالث: الثنوع الأسلوبي بين الاسمية والفعلية} و يعد هذا المطلب مكملاً للذي سبقه، فالقصة القرآنية كما نوعت بين الجمل البسيطة والمر كبة، و كانت

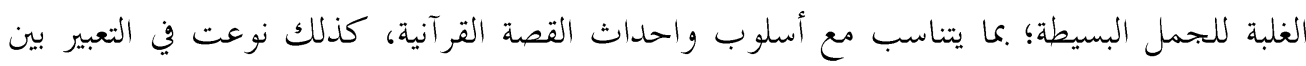
الجملة الاسمية والفعلية، ولاسيما في المكية منها. وعامة فان الجملة الفعلية تحمل دلالة تختلف عن دلالة الجمملة الاسمية، فقد فرق (النحاة وغيرهم بين الجملة الاسمية والفعلية، فالجملة الفعلية تدل على التجدد والحدوث وأما الجملة الاسمية فتدل على الثبوت

$$
\text { والاستمرار)(19). (19). }
$$

ولو نظرنا اللى التحليل الجملي السابق لرأينا أن الجمل الفعلية هي الغالبة في سياق قصة قارون، إذ كان عدد الجمل الفعلية فيها احدى وثلاثين جملة، في حين أن عدد الجمل الاسمية هو أربع عشرة جملة، وان انديان غلبة الجمل الفعلية هو ما يناسب الحوار في القصة، والحركة في الاحداث. ومن خلال هذا التنوع في

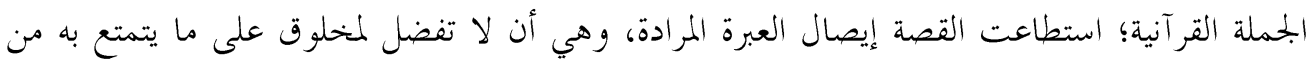

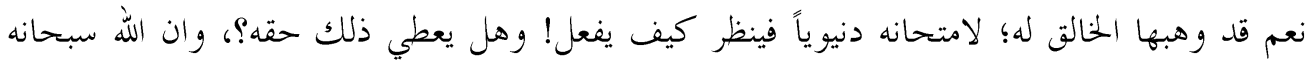

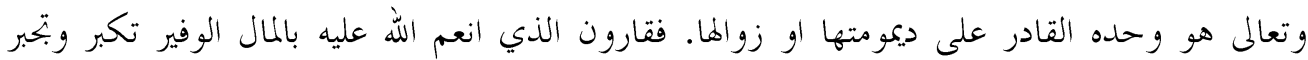
و انكر افضال الله عليه، ولم يستمع لنصائح قومه الذين انبهر قسم منهم بما كان عليه قارون من النعم

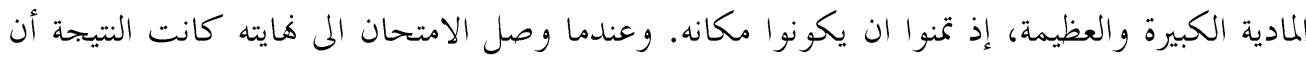

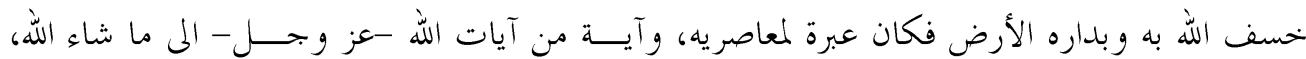
حتى صار مثلاً (20.

ولتوضيح ذلك التنوع الاسلوبي في سياق القصة القر آنية بشكل أكبر، فإننا سنأخذ قصة أخرى، وهي قصة أبينا إبراهيم (علية السلام) مع النمرود، وهي عبارة عن قصة حوارية بالدرجة الأولى، وقد وردت 
هذه القصة في سياق سورة البقرة، وسورة البقرة مدنية، وتحمل سمات السور المدنية، ولاسيما فيما يخص طول الجملة القر آنية والتفصيل و البيان، إلا إننا سنجد أن التنوع فيها بين الاسمية والفعلية، كان مشاهاً لما عرضناه -سلفا- في سياق قصة سورة القصص المكية، و كما يأتي:

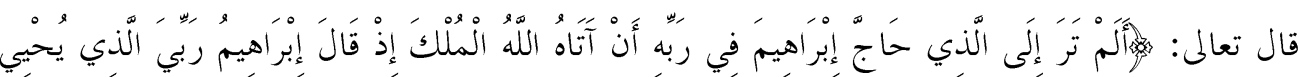

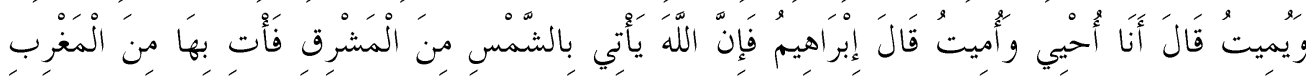

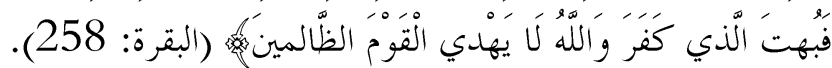

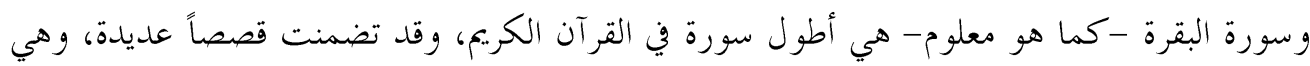
قصة آدم والشجرة وإبليس، وموسى وقومه الذين اتخذوا العجل الهاً، وموسى والبقرة، وموسى هور

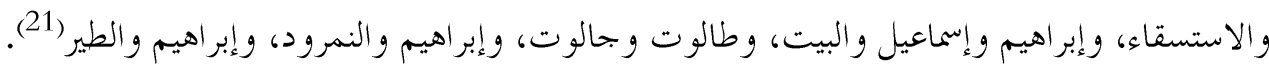
ومن سماها ايضاً اها سورة الأحكام والتكاليف، ووع ذلك نلاحظ كثرة القصص التي وردت فيها؛ وذلك لان موضوع السورة الرئيس هو احكام العقل في تدبير شؤون العباد، وهذه القصص جميعها تؤيد

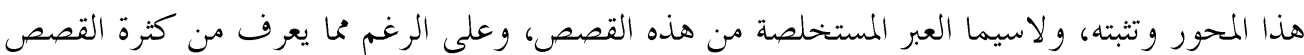
في السور المكية خحلافاً للمدنية؛ وذلك لأن الحاجة ماسة في المكية الم تثبيت العقيدة في النفوس المؤمنة

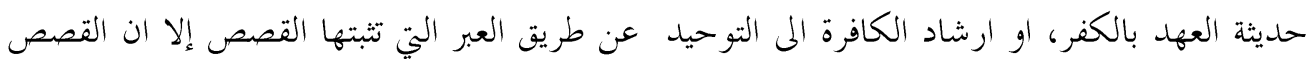

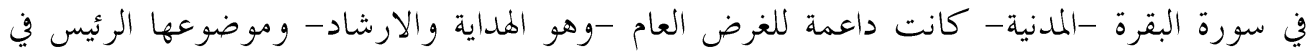
تثبيت الأحكام، وبناء المجتمع السليم المتماسك (22.

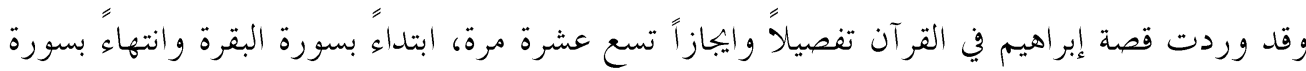

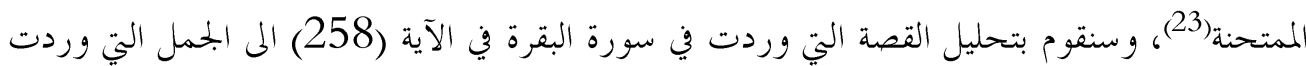

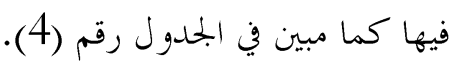

الحدول رقم (4) تحليل قصة إبراهيم في سورة البقرة

\begin{tabular}{|c|c|c|}
\hline نوعها & الجملة & ت \\
\hline فعلية & الم تر الى الذي & 1 \\
\hline فعلية & حاج إبراهيم في ربه & 2 \\
\hline فعلية & أتاه الله الملك & 3 \\
\hline |سمية & ربي الذي يحيي ويميت & 4 \\
\hline فعلية & يجيي & 5 \\
\hline
\end{tabular}




\begin{tabular}{|c|c|c|}
\hline فعلية & يميت & 6 \\
\hline فعلية & قال & 7 \\
\hline اسمية والخبر فيها جملة فعلية & انا احيي واميت & 8 \\
\hline فعلية & قال إبر اهيم & 9 \\
\hline اسمية والخبر فيها جملة فعلية & ان الله يأتي بالشمس من المشرق & 10 \\
\hline فعلية & فأت ها من المغرب & 11 \\
\hline فعلية & فبهت الذي كفر & 12 \\
\hline اسمية والخبر فيها جملة فعلية & الله لا يهدي القوم الظالمين & 13 \\
\hline
\end{tabular}

وهكذا نلاحظ أن القصة تكونت من ست عشرة جملة، أربع جمل اسمية، واثني عشرة جملة فعلية،

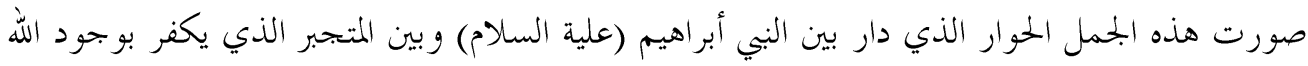

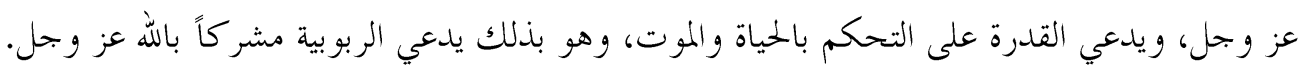

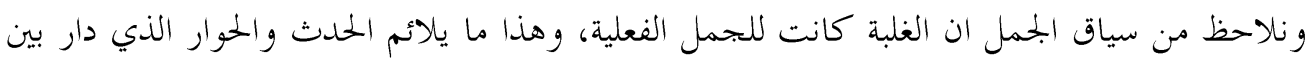
الاثنين (قال الأول، يجب الثاني وهكذا...) مع أنه حوار شديد حول مبدأ مهم واساسي، وهو مبدأ العقيدة والتوحيد. وقد بدأت القصة بجملة فعلية مصدرة بأسلوب الاستفهام الإنكاري (ألم تر؟)، وهذا الأسلوب يؤدي الى لفت الانتباه، واستذكار ما سوف يتبعه من تفصيل. وتصدير الجمملة بالفعل (ترى) يؤثر في نفس المتلقي،

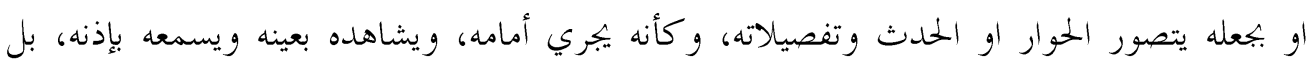

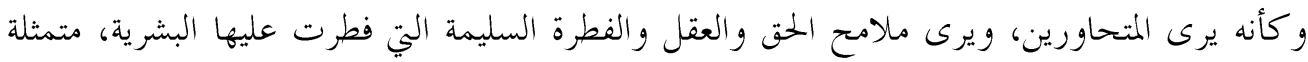

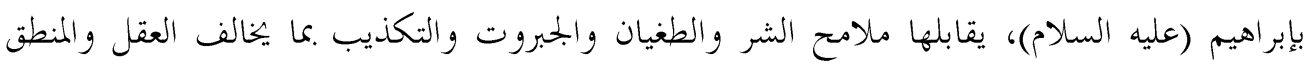
المتمثل بالكافر المتجبر الذي يرفض وجود إله يتحكم هذا الكون الهائل الهيل العظيم.

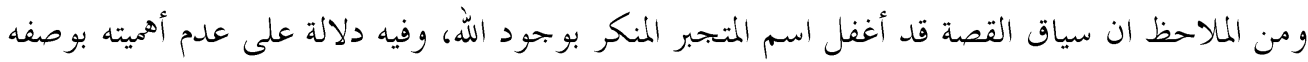

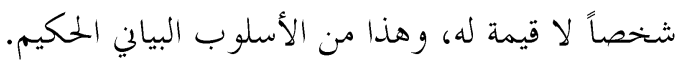
و نلاحظ ذلك التشابه في بناء جمل القصة القرآنية في السور المكية، والمدنية في غلبة الجمل الفعلية، ولالا

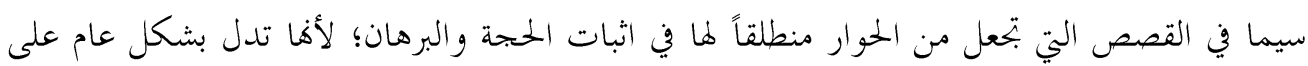
المرونة الواسعة في الدلالات. 
واذا نظرنا المى الجمل الاسمية الأربع التي وردت في القصة نلاحظ ان ثلاث منها وهي (ربي الذي يحيي

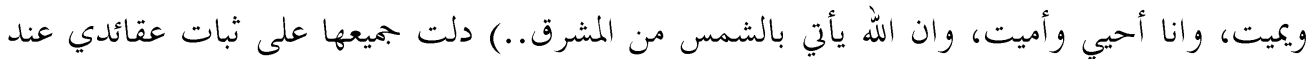
إبراهيم (علية السلام) و كذلك النمرود، ودلت الأخيرة على حقيقة ثابتة دائمة بدوام الليل والنهار.

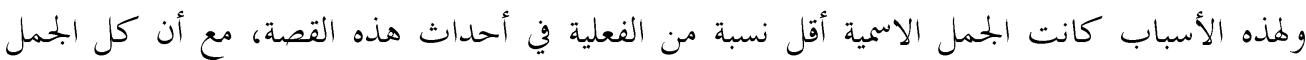

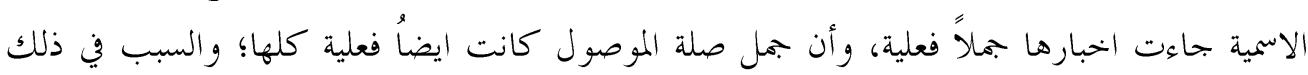

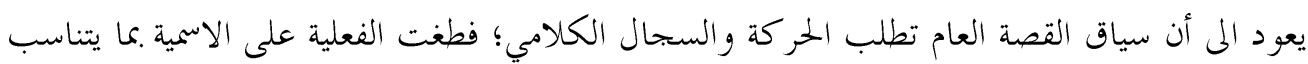
مع ذلك الغرض. أما خاتمة القصة، وهي جملة (والله لا يهدي القوم الظالمين)، فكانت خير ما يختم به لمثل هذه الجمل،

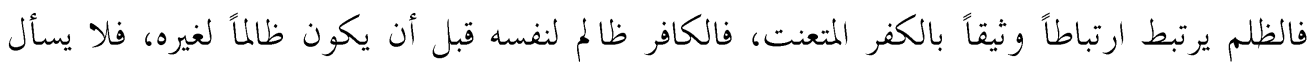

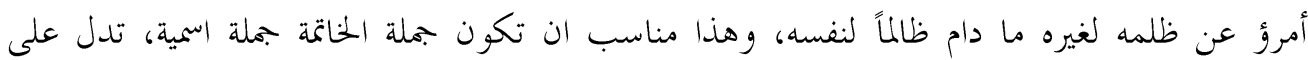
الثبوت في الحكم في عدم حصول الهداية لكل من يظلم نفسه، فظلا عن غيره، فحققت أرقى أوجه المطابقة بين جمل القصة ومحتو اها. وهكذا بند ان القصة القر آنية قد اتخذت مناح أسلو بية عديدة، منها أها غلبت الجملة الفعلية على الاسمية

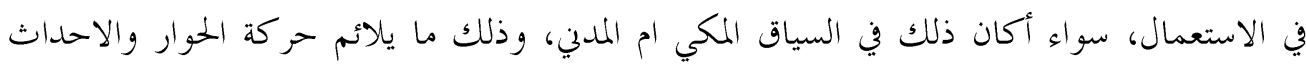
المترتبة في القصة القرآنية، وسواء أكانت الجملة قصيرة أم طويلة، بسيطة أم مركبة.

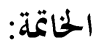
بعد حمد الله -عزز وجل - على تفضله بإتمام هذا البحث؛ لابد من ذكر أهم النتائج التي توصل اليها، ويمكن الجمالها فيما يأتي: 1. إن السياق في القصة القر آنية قد استعمل الجملة بأنماطها المختلفة بشكل دقيق جداً، وهذا أسهم بشكل فاعل في اتساقها لفظياُ ودلالياً. 2. إن القصص القرآني أكثر وروداً في السور المكية من المدنية، فسورة ص مثلاً هي من السور المكية والتي تنطبق عليها خصائص السور المكية، قد ورد فيها أربع قصص، وهي (داود والخصمان، وسليمان، وأيوب، آدم وإبليس) 3. إن ما يميز القصص المكية هو قصر جملها، وتتابعها متسارعة، ذات إيقاع سريع ومختصر،

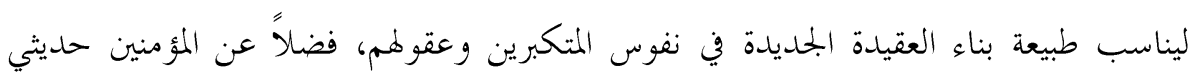
العهد بهذا الايمان و الدين. 
4. إن الاتساق الفظي للجمل في قوالب معينة بحسب طبيعة القصة القرآنية هو الذي يعطيها ذلك ح. التأثير وتلك الدلالة في اجتماع جمل السياق جميعها. 5. إن الغلبة كانت للجمل البسيطة في سياق القصة القرآنية، مع عدم اغفال دور الجمل المركبة في ربطها للأحداث في القصة التي تبتعد عن التفصيل وتذكر الضروري منها؛ وذلك لتغيير المفاهيم و بناء العقيدة الصحيحة. 6. من خلال تحليل جمل القصص القرآنية تبين ان الغالب بالاستعمال هو نمط الجملة الفعلية بشكل لافت للنظر، وذلك لقدرة الجمملة الفعلية على التعبير عن الاحداث وتتبعها وبيان الحركة،

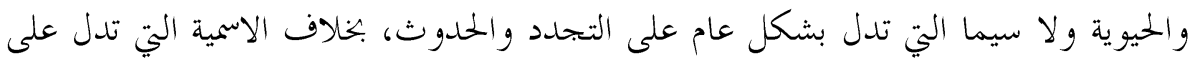
الثبوت و الدوام. و ونلاحظ ذلك في سياق القصص المكية او المدنية على السواء.

1. ابن عطية الأندلسي (ت 542 هـ)، المحرر الوجيز في تفسير الكتاب العزيز، تعقيق عبد السلام عبد الشافي، دار الكتب العلمية، بيروت، ط1، 1422

2. ابن قتيبة ابو محمد بن عبدالله بن مسلم الدنيوري (ت 276هـ)، تأويل مشكل القرآن، تحقيق: ابراهيم شمس الدين، دار الكتب العلمية، بيروت، لبنان.

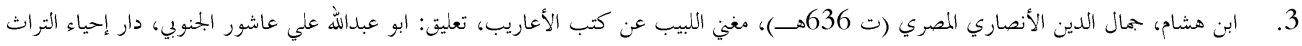

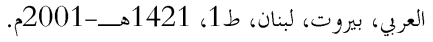

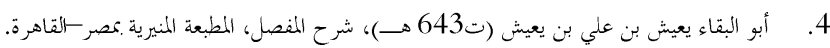

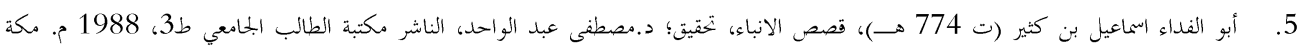

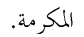

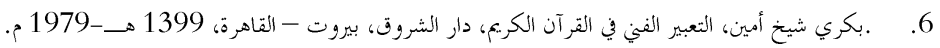

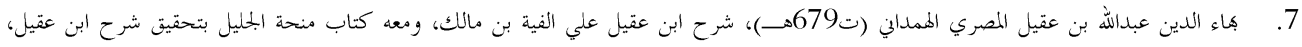

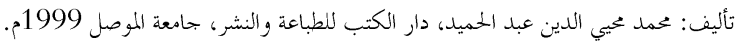

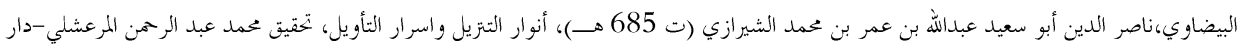

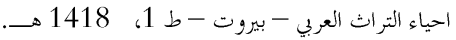

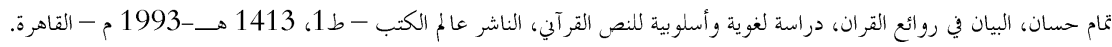

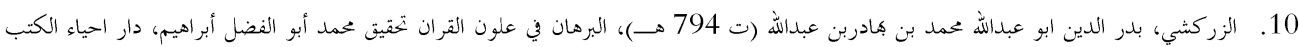

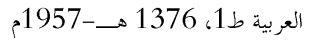

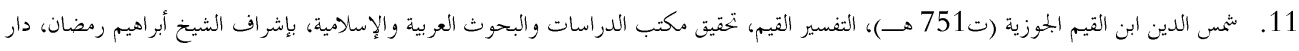

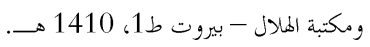

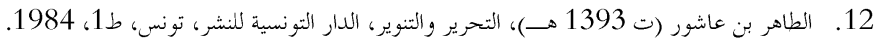

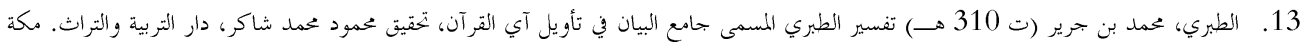
المكرمة.

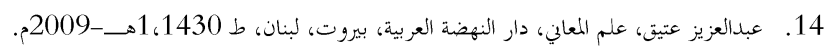

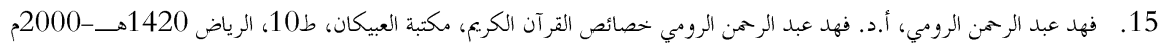

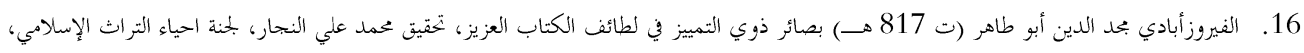




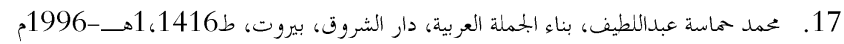

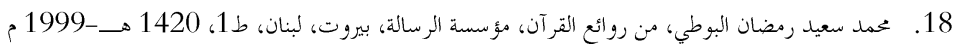

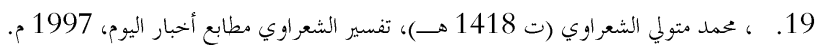

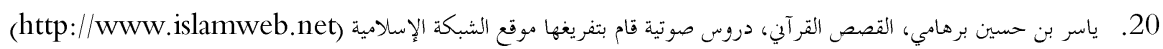

(1) يمكن الرجوع الى كتب التفسير والقصص القرآني؛ للوقوف على ما يخص الأبعاد الفنية والأدبية والإعجازية للقصة القرآنية ومنها على سبيل المثال: كتاب

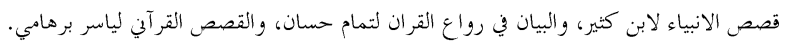

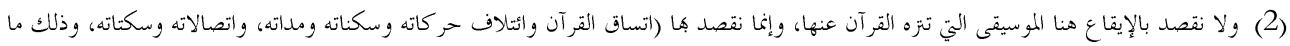

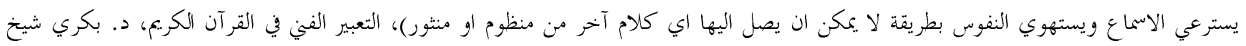
أمين: 190 (3) ينظر: شرح المفصل: ابن يعيش:

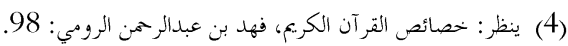

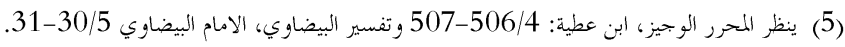

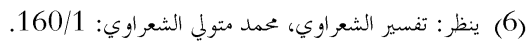

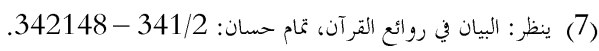

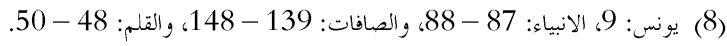

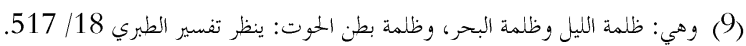
(10) ينظر: شرح ابن عقيل: 142/2.

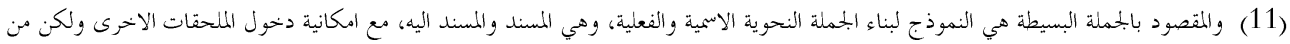

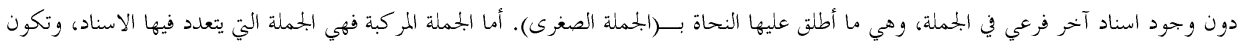

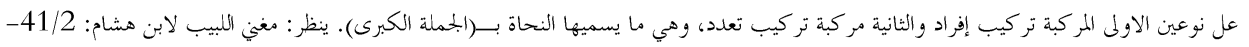

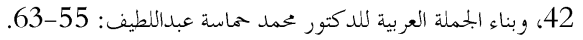

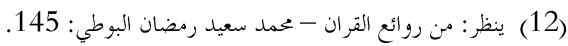

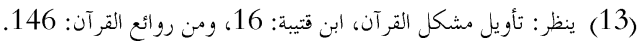

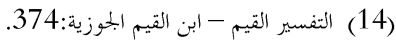

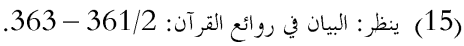

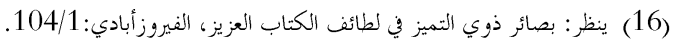

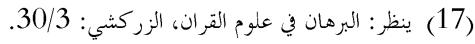

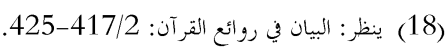

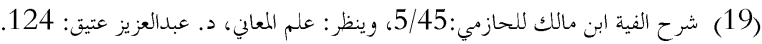

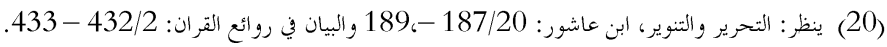

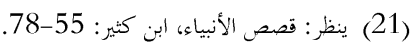

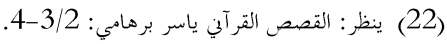

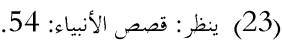

